\title{
Video Article \\ One-step Metabolomics: Carbohydrates, Organic and Amino Acids Quantified in a Single Procedure
}

\author{
James D. Shoemaker ${ }^{1}$ \\ ${ }^{1}$ Edward A. Doisy Department of Biochemistry and Molecular Biology, Saint Louis University School of Medicine
}

Correspondence to: James D. Shoemaker at shoemajd@slu.edu

URL: https://www.jove.com/video/2014

DOI: doi:10.3791/2014

Keywords: Biochemistry, Issue 40, metabolomics, gas chromatography/mass spectrometry, GC/MS, inborn errors, vitamin deficiency, BNA analyses, carbohydrate, amino acid, organic acid, urease

Date Published: 6/25/2010

Citation: Shoemaker, J.D. One-step Metabolomics: Carbohydrates, Organic and Amino Acids Quantified in a Single Procedure. J. Vis. Exp. (40), e2014, doi:10.3791/2014 (2010).

\section{Abstract}

Every infant born in the US is now screened for up to 42 rare genetic disorders called "inborn errors of metabolism". The screening method is based on tandem mass spectrometry and quantifies acylcarnitines as a screen for organic acidemias and also measures amino acids. All states also perform enzymatic testing for carbohydrate disorders such as galactosemia. Because the results can be non-specific, follow-up testing of positive results is required using a more definitive method. The present report describes the "urease" method of sample preparation for inborn error screening. Crystalline urease enzyme is used to remove urea from body fluids which permits most other water-soluble metabolites to be dehydrated and derivatized for gas chromatography in a single procedure. Dehydration by evaporation in a nitrogen stream is facilitated by adding acetonitrile and methylene chloride. Then, trimethylsilylation takes place in the presence of a unique catalyst, triethylammonium trifluoroacetate. Automated injection and chromatography is followed by macro-driven custom quantification of 192 metabolites and semi-quantification of every major component using specialized libraries of mass spectra of TMS derivatized biological compounds. The analysis may be performed on the widely-used Chemstation platform using the macros and libraries available from the author. In our laboratory, over 16,000 patient samples have been analyzed using the method with a diagnostic yield of about $17 \%$--that is, $17 \%$ of the samples results reveal findings that should be acted upon by the ordering physician. Included in these are over 180 confirmed inborn errors, of which about $38 \%$ could not have been diagnosed using previous methods.

\section{Video Link}

The video component of this article can be found at https://www.jove.com/video/2014/

\section{Protocol}

\section{Procedure for Processing Urine Samples}

1. Thaw the urine sample in a $37^{\circ} \mathrm{C}$ water bath. Decant into a new container if the original is compromised

2. Take a maximum aliquot of $13 \mathrm{ml}$ of sample and store it at $-20^{\circ} \mathrm{C}$ in a labeled conical centrifuge tube.

3. Measure and record the optical density of the sample by placing a couple of drops of urine in the refractometer.

4. Filter the sample through a 0.2 um filter.

5. Measure out the volume of sample below according to the optical density

\begin{tabular}{|l|l|}
\hline $1.000-1.009$ & $1.00 \mathrm{ml}$ \\
\hline $1.010-1.019$ & $0.50 \mathrm{ml}$ \\
\hline $1.020-1.050$ & $0.25 \mathrm{ml}+0.25 \mathrm{ml} \mathrm{H}_{2} \mathrm{O}$ \\
\hline
\end{tabular}

6. The specified volume is then transferred to a Reactivial containing the following internal standards: 500 nanomoles (nmoles) ${ }_{3}$ Creatine; 10 nmoles $d_{3}$ Methylmalonic acid; 100 nmoles each of the following ${ }^{13} C_{3}$ lactate, ${ }^{13} C_{3}$ pyruvate, ${ }^{13} C_{2}{ }^{15} \mathrm{~N}$ glycine, $d_{3}$ serine, $d_{5}$ phenylalanine, $d_{11}$ hexanoylglycine, ${ }^{15} \mathrm{~N}_{2}$ orotate, $\mathrm{d}_{4}$ sebacic acid, ${ }^{13} \mathrm{C}_{6}$ glucose, $\mathrm{d}_{6}$ inositol and $\mathrm{d}_{5}$ tryptophan.

7. 20 microliters $(\mu \mathrm{l})$ of a 7.5 Units/ $\mu \mathrm{l}$ solution of urease (Calzyme Laboratories catalog no. 116A0100) is added to the sample, which is then flushed and sealed under $\mathrm{CO}_{2}$ through an inert septum.

8. The sample is held at $37^{\circ} \mathrm{C}$ for 30 minutes with more carbon dioxide gas added at 15 minute intervals to maintain pressure.

9. $20 \mu \mathrm{l}$ more of the urease solution is added, the vial is flushed with carbon dioxide, and the sample maintained at $37^{\circ} \mathrm{C}$ for another 15 minutes.

10. $500 \mu \mathrm{l}$ of $30: 70$ acetone : methanol is added, the rubber septum is replaced with a Teflon coated septum, and the sample is chilled at $-20^{\circ} \mathrm{C}$ for 15 minutes.

11. Solids are removed by centrifugation at $1500 \mathrm{rpm} \times 10$ minutes then decanted into a clean $2.0 \mathrm{cc}$ Reactivial (Supelco/Sigma)

12. Add triethylammonium trifluoroacetate (TEA/TFA) (Sigma) as follows:
- $20 \mu \mathrm{l}$ for $1.00 \mathrm{ml}$ samples 
- $40 \mu \mathrm{l}$ for $0.5 \mathrm{ml}$, or less, samples

13. Top off with acetonitrile and place under a nitrogen stream at $70^{\circ} \mathrm{C}$ until constant volume is achieved (TEA/TFA will remain) ( $\sim 15$ minutes).

14. Repeat step 13, up to 4 times until a precipitate forms ( 10 minutes each).

15. Let cool for about 2 minutes. Top off with methylene chloride, being careful of boil over, and dry ( 4:00 minutes).

16. Repeat step 15.

17. Add MSTFA (N-methyl-N-trimethylsilyltrifluoroacetamide) (Thermal Scientific) at the following rates:

- $150 \mu \mathrm{l}$ for $1.00 \mathrm{ml}$ samples

- $200 \mu \mathrm{l}$ for $0.50 \mathrm{ml}$, or less, samples

18. Cap under a nitrogen atmosphere and incubate at $70^{\circ} \mathrm{C}$ for 1 hour.

19. Transfer to microvials, under a nitrogen atmosphere, for analysis on gas chromatograph /mass spectrometer.

20. Place microvials for automated injection by the Agilent $5975 \mathrm{GC} / \mathrm{MS}$ : Instrument temperatures are: injector $200^{\circ} \mathrm{C}$, interface $250^{\circ} \mathrm{C}$, oven $80^{\circ} \mathrm{C}$ for 1 minute; ramp at $4^{\circ} \mathrm{C} /$ minute $80-130^{\circ} \mathrm{C}$, ramp at $6^{\circ} \mathrm{C} /$ minute $130-200^{\circ} \mathrm{C}$, ramp at $12^{\circ} \mathrm{C} /$ minute $200-285^{\circ} \mathrm{C}$, hold for 10 minutes. Column: 25 m, 320 micron ID, 0.5 micron film thickness DB-5. Mass Spec: source $230^{\circ} \mathrm{C}$, quad $150^{\circ} \mathrm{C}$, Scan $50-650$ amu at 2.46 scans/sec. Solvent delay 3.5 minutes.

\section{Representative Results}

Please click here to see the representative results.

\section{Discussion}

The urease method (1) has been cited 62 times in the medical literature with various modifications. Matsumoto's group $(2,3)$ simplified the procedure for high-throughput neonatal screening and reported the results from 16000 patients. Kuhara and others (4-7) have reported the use of the method in several cases of inborn error diagnosis and follow-up. Rhead (8) also confirmed the method's utility for clinical diagnosis and follow-up of inborn errors. The method has been applied to urine of bears, knock-out mice, elephants and homogenates of whole fruit flies and their larvae (9). Culture media from Cryptococcus before and after site-directed mutagenesis were also analyzed, without the urease step (10). The method has been applied to human nutritional assessment in medical students, Down syndrome patients and demented elderly veterans after loading the subjects with oral doses of the amino acids tryptophan, methionine and isoleucine (11). All eight B-vitamins were assessed by quantifying the breakdown products of the three amino acids which, among them, require all 8 vitamins at some point in their degradation. The toxic effects of pharmaceuticals and their mitigation by vitamin supplementation has been reported (12). Amniotic fluid samples from normal and Down syndrome pregnancies were analyzed and reported (13-15).

\section{Disclosures}

The Metabolic Screening Lab is a CLIA-licensed clinical laboratory owned by Saint Louis University, a non-profit corporation. Dr. Shoemaker does not directly profit from laboratory revenues, but may benefit indirectly from laboratory productivity. None of the methods, techniques, results, normal ranges, macros, software, libraries or conclusions are considered proprietary and are freely available to interested parties.

\section{Acknowledgements}

The able technical assistance of Anthony Thomas is gratefully acknowledged.

\section{References}

1. Shoemaker, J.D., Elliott, W.H. Automated screening of urine samples for carbohydrates, organic and amino acids after treatment with urease. J. Chromatogr. 562 (1-2) 125-38, (1991).

2. Kuhara, T., Shinka, T., Inoue, Y., Ohse, M., Zhen-wei, X., Yoshida, I., Inokuchi, T., Yamaguchi, S., Takayanagi, M., Matsumoto, I. Pilot study of gas chromatographic-mass spectrometric screening of newborn urine for inborn errors of metabolism after treatment with urease $\mathrm{J}$ Chromatogr B Biomed Sci Appl. 731 (1) : 141-7, (1999).

3. Fu, X., Iga, M., Kimura, M., Yamaguchi, S. Simplified screening for organic acidemia using GC/MS and dried urine filter paper: a study on neonatal mass screening. Early Hum Dev. 58 (1) : 41-55 (2000).

4. Kuhara, T., Ohdoi, C., Ohse, M. Simple gas chromatographic-mass spectrometric procedure for diagnosing pyrimidine degradation defects for prevention of severe anticancer side effects. J Chromatogr B Biomed Sci Appl. 758 (1) : 61-74 (2001).

5. Kuhara, T. Diagnosis of inborn errors of metabolism using filter paper urine, urease treatment, isotope dilution and gas chromatography-mass spectrometry. J Chromatogr B Biomed Sci Appl. 758 (1) : 3-25 (2001).

6. Iga, M., Kimura, M., Ohura, T., Kikawa, Y., Yamaguchi, S. Rapid, simplified and sensitive method for screening fructose-1,6-diphosphatase deficiency by analyzing urinary metabolites in urease/direct preparations and gas chromatography-mass spectrometry in the selected-ion monitoring mode. J Chromatogr B Biomed Sci Appl. 746 (1) : 75-82, (2000).

7. Kuhara, T., Ohse, M., Ohdoi, C., Ishida, S. Differential diagnosis of homocystinuria by urease treatment, isotope dilution and gas chromatography-mass spectrometry. J Chromatogr B Biomed Sci Appl. 742 (1) : 59-70 (2000).

8. Young, V., Lo, S., Shoemaker, J., Thomas, A., and Rhead, W. Validation and Extension of the Urease Method for Urine Organic and Amino Acid Analysis. Society for Inherited Metabolic Disorders Annual Meeting, March, Asilomar, California (2008). 
9. Smith, E.M., Hoi, J.T., Eissenberg, J.C., Shoemaker, J.D., Neckameyer, W.S., Ilvarsonn, A.M., Harshman, L.G., Schlegel, V.L., Zempleni, J. Feeding Drosophila a biotin-deficient diet for multiple generations increases stress resistance and lifespan and alters gene expression and histone biotinylation patterns. J Nutr. 137 (9) : 2006-12 (2007).

10. Brown, S.M., Shoemaker, J.D., Lodge, J.K. The Importance of NADP ${ }^{+}$-Dependent Isocitrate Dehydrogenase in Resistance to Nitrosative Stress and the Inessentiality of Glucose-6-Phosphate Dehydrogenase for Oxidative Stress Resistance in Cryptococcus neoformans. Eukaryotic Cell (2010).

11. Shoemaker, J.D. Nutritional Screening in Humans by Gas Chromatography-Mass Spectrometry of Urine Metabolites After Substrate Loading. Universidad Nacional Autonoma de Mexico, Inst. Nal. de Pediatria, Unidad de Genetica de la Nutricion, Mexico City, Mexico, April, (1992).

12. Baggot, P.J., Kalamarides, J.A., Shoemaker, J.D. Valproate-induced biochemical abnormalities in pregnancy corrected by vitamins: A Case Report, Epilepsia, 40(4)512-5, (1999).

13. Baggot, P.J., Eliseo, A.J., Kalamarides, J.A., Shoemaker, J.D. A folate-dependent metabolite in amniotic fluid from pregnancies with normal or trisomy 21 chromosomes. Fetal Diagn Ther. 21(1):148-52, (2006).

14. Baggot, P.J., Eliseo, A.J., DeNicola, N.G., Kalamarides, J.A., Shoemaker, J.D. Organic acid concentrations in amniotic fluid found in normal and Down syndrome pregnancies. Fetal Diagn Ther. 23 (3) : 245-8. (2008)

15. Baggot, P.J., Eliseo, A.J., DeNicola, N.G., Kalamarides, J.A., Shoemaker, J.D. Pyridoxine-related metabolite concentrations in normal and Down syndrome amniotic fluid. Fetal Diagn Ther. 23 (4) : 254-7 (2008). 